\author{
Research Article
}

\title{
HERBAL LEPA FORMULATION PREPARATION AND ITS EVALUATION
}

\section{Tejaswini Singh}

Founder, Organic Greens Products and Botaniqal Naturopathy Consultancy, Lucknow, Uttar Pradesh, India.

\begin{tabular}{|c|c|}
\hline Article info & ABSTRACT \\
\hline Article History: & The concept of beauty is as old as humanity itself. Herbs have been used for beautification \\
\hline Received: 10-05-2021 & from historic times and have also been described in Ayurvedic literature. Herbs as whole or \\
\hline Revised : 06-07-2021 & herbal extracts have been used to treat the various ailments of the skin, hair, body odor, \\
\hline $\begin{array}{l}\text { Accepted: } 20-08-2021 \\
\text { Published: } 18-09-2021\end{array}$ & and overall beautification. The demand for Ayurveda in cosmetology is established because \\
\hline KEYWORDS: & it is effective, cheaper, and long-lasting without any side effects. The present study aimed to \\
\hline Lepa, Ayurvedic & formulation. The dried powder of herbs was procured \\
\hline $\begin{array}{ll}\text { formulation, } & \text { Face } \\
\text { pack, Cream, Skin } \\
\text { dryness. }\end{array}$ & $\begin{array}{l}\text { and physio-chemical properties. Lepa was prepared by mixing powder with cream base to } \\
\text { the desired consistency and leaving it overnight for before its application. Lepa } \\
\text { formulations exhibited slight alkaline properties }(\mathrm{pH} 7.6) \text {, spreading ability }\left(19.63 \mathrm{~cm}^{2}\right) \text {, and } \\
\text { non-irritating properties. The Lepa formulation contains a variety of natural components in } \\
\text { the appropriate and desired quantities for greater efficacy. The developed herbal Lepa } \\
\text { formulation has shown satisfactory properties without the necessity of further } \\
\text { moisturizing cream. }\end{array}$ \\
\hline
\end{tabular}

\section{INTRODUCTION}

The most ancient medical science known to humanity is the Ayurveda. It is also known as the art of life. The basic requirements for all living beings are health and longevity. Bhaishajya (Medicine) is among the four pillars of therapy and the treatment of the illness and its medical management. The Bhaishajya (Medicine) is administered to the patients in different forms and modulations according to the need. The branch of Ayurvedic Pharmaceutical Sciences has been modifying dosage forms in an effort to reduce dosage and increase compliance among patients. ${ }^{[1]}$

Medicines that are in the form of a paste and applied externally (to the skin or mucosa) are called Lepas. Lepa Kalpana (powder formulation), even to this day, though a secondary formulation, it continues to be a very popular option due to its convenience for external use. Lepa kalpana is described both as Chikitsa for the treatment of skin diseases and a beauty regimen.

\begin{tabular}{|l|l|}
\hline \multicolumn{3}{|c|}{ Access this article online } \\
\hline Quick Response Code & \begin{tabular}{l} 
https://doi.org/10.47070/ijapr.v9i8.1882 \\
\hline
\end{tabular} \\
\cline { 2 - 3 }
\end{tabular}

When one or more than one drug is ground into fine powder before being mixed with a suitable liquid to give a paste like consistency, the preparation is called a Lepa. The Lepa preparations are best known for 'Vrna Shodhana' (wound cleaning) and 'Vrna ropana' (wound healing).[2,3,4]

Mukha Lepa is one of the oldest and most effective methods of beautification. Mukha Lepa is applied evenly all over the face and allowed to dry. After it dries, its cleansed using water and the skin is moisturized with oil or creams to improve its condition. Each type of skin requires a different type of Mukha Lepas. In addition to improving skin texture, Lepas also improve blood circulation within facial veins. The Mukha Lepas remedy can be used both to prevent and to treat any skin condition or problem. ${ }^{[5,6]}$ The drawback with the current Lepa formulation is that, post its application the skin needs to be moisturized with oil or creams to prevent skin dryness. Thus, to address this limitation and to eliminate the step of skin moisturizing post-Lepa application, I have developed a new Lepa formulation prepared from natural herbs and evaluated for its effectiveness.

Herbs used for fairness of skin are as below. 


\section{MATERIALS AND METHODS}

\section{Raw Material Procurement}

Herbs components as mentioned in the Table 1 has been purchased from the local Ayurvedic stores in Lucknow.

Table 1: Composition of Lepa

\begin{tabular}{|c|l|l|l|l|l|}
\hline S. No & Ingredients & Botanical Name & Part Used & Form & Qty Taken (gm) \\
\hline 1 & Matcha Tea & Camellia sinensis & Leaves & Powder & 10 \\
\hline 2 & Green tea & Camellia sinensis & Leaves & Powder & 20 \\
\hline 3 & Gulab & Rosa hybrida & Petals & Powder & 2 \\
\hline 4 & Gendha & Tagetes erecta & Petals & Powder & 2 \\
\hline 5 & Lemon Peel & Citrus limon & Peel & Powder & 15 \\
\hline 6 & Dal-Chini & Cinnamomum & Bark & Powder & 20 \\
\hline 7 & Saunf & Foeniculum vulgare & Seeds & Powder & 20 \\
\hline 8 & Mulethi & Glycyrrhiza glabra & Rhizome & Powder & 5 \\
\hline 9 & Chandan & Santalum album & Heartwood & Powder & 1 \\
\hline 10 & Coffee & Coffea arabica & seeds & Powder & 0.5 \\
\hline 11 & Elaichi & Elettaria cardamomum & seeds & Powder & 1 \\
\hline 12 & Jaifal & Myristica fragrans & fruit & Powder & 0.5 \\
\hline 13 & Neem & Azadirachta indica & Leaves & Powder & 0.5 \\
\hline 14 & Tulsi & Ocimum tenuiflorum & Leaves & Powder & 2 \\
\hline 15 & Kesar & Crocus sativus & Stigma & Powder & 0.1 \\
\hline 16 & Adrak & Zingiber officinale & Rhizome & Powder & 0.1 \\
\hline 17 & Pomegranate Seed & Punica granatum & Seeds & Powder & 0.1 \\
\hline 18 & Mosambi Seed & Citrus limetta & Seeds & Powder & 0.2 \\
\hline 19 & Lemon Oil & Citrus limon & Peel & Oil & 0.25 \\
\hline 20 & Fennel Seed Oil & Foeniculum vulgare $p$ & Seeds & Oil & 0.25 \\
\hline 21 & Lavender Oil & Lavandula angustifolia & Flower & Oil & 0.25 \\
\hline
\end{tabular}

\section{Formulation of Lepa cream}

Using \#40 mesh, the powdered ingredients (Table 1) were sieved and accurately weighed, then mixed geometrically to ensure even mixing. In order to evaluate it, the product was placed in an airtight container. Lepa cream is prepared by mixing powder mixtures with cream base (beeswax, cocoa butter, shea butter, and aloe vera gel) in desired consistency of making soft cream. The prepared mixture was then placed in the refrigerator overnight before application.

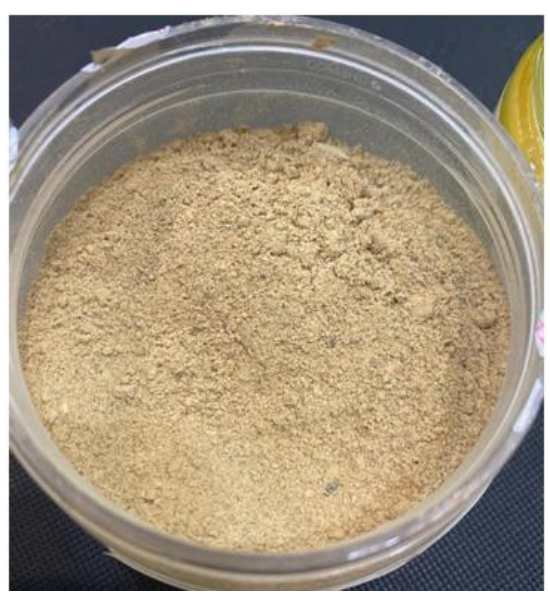

Powder

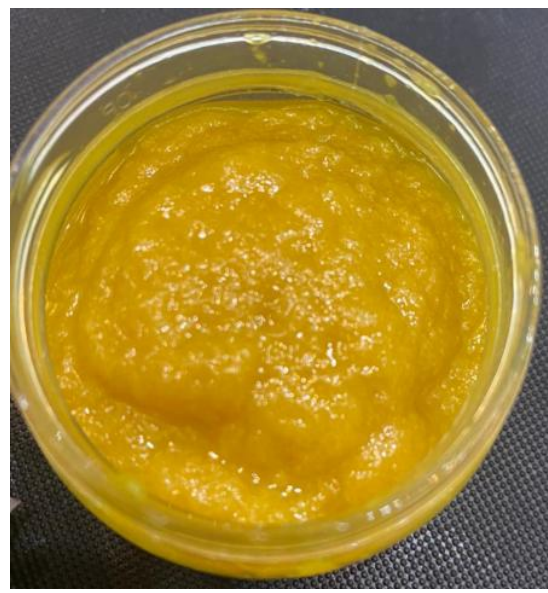

Cream Base

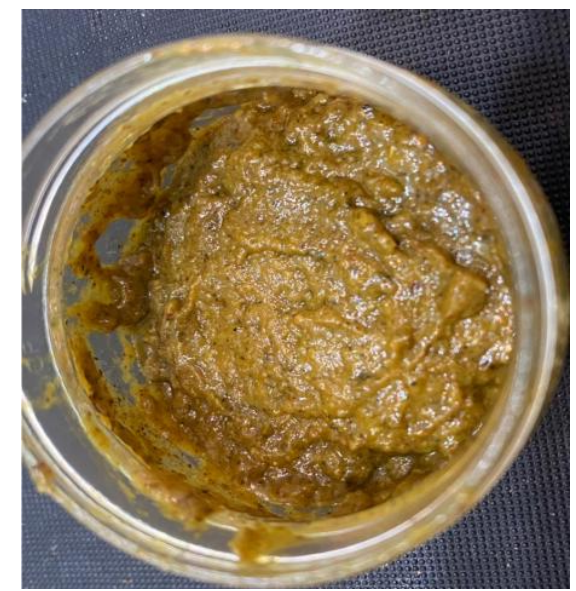

Lepa Cream

Figure 1: Powder, Cream Base and Lepa Cream (formulation) 


\section{Skin Irritation Test}

Skin irritation test was performed to determine skin sensitivity by applying Lepa and its routine structures to intact skin. Following application, the Lepa was kept in contact with intact skin for 15 minutes and then washed off with normal water. The process lasted for one week. Redness, rashes, burning sensations, itching, and other unfavorable reactions were observed on the skin. In addition, the Lepa formulation left the skin smooth with no signs of skin dryness normally associated with Lepas.

\section{Pharmaceutical Study}

A range of physio-chemical properties, such as colour, smell, consistency, texture, spreadability, loss on drying, ash value, and $\mathrm{pH}$, were measured. The results are depicted in Table 2.

\section{Spreadability and Spreading Coefficient}

A wooden board with scale and two glass slides, one of which was attached to the wooden board, were used to determine the spreading coefficient (spreadability) of the formulas. Another was movable, attached to a cord that passed through a pulley and carried a weight. A sample of formulation (1g) was placed between two glass slides. Weight $(100 \mathrm{~g})$ was placed on the upper slide and allowed to rest for 5 minutes to provide a uniform film of the formulation. The weight was removed, and the top slide was subjected to a pull obtained by attaching a $30 \mathrm{~g}$ weight over the pulley. The time (sec) required for the slide to travel a pre-marked distance was recorded.[7] Spreadability is calculated by using the following formula:

\section{$\mathrm{S}=\mathrm{M} * \mathrm{~L} / \mathrm{T}$}

The weight tied to the upper slide is $M$, the length of the glass slides is $\mathrm{L}$, and the time taken to separate the slides is $\mathrm{T}$.

\section{Loss on Drying}

A petri dish was weighed first and then $50 \mathrm{~g}$ of a test sample was added. The weight of the petri dish with the added sample was also noted. Next, it was placed in a hot air oven set to $105^{\circ} \mathrm{C}$. Based on the following formula, the dry loss was calculated:

Loss on drying $=\mathrm{Wt}$. before heating $-\mathrm{Wt}$. after heating \% Loss on Drying = Loss on Drying/ Wt. before Heating * 100

\section{RESULTS AND DISCUSSIONS}

In order to add good cosmetic value to the powder, it was made of fine quality. The cream base has moisturizing, rich ingredients. The results of the evaluation parameters have been mentioned in table 2 . Characterization of the formulation was done for its organoleptic, physiochemical properties, and skin irritation. The formulation has been tested for its colour, odor, touch, consistency, texture, spread ability, moisture content, and ash value. Additionally, the skin irritation test was also performed for the formulation.

Based on the analysis of $\mathrm{pH}$ and Spread ability, it was found that the $\mathrm{pH}$ of the Lepa formulation was 7.4 to 7.6 , and the spreadability was $19.68 \mathrm{~cm}^{3}$. Having a greasy texture, characteristic odor, soft consistency, and gritty texture, the formulation is lightweight. The total ash value was found to be $1 \%$, and moisture content was $14.5 \mathrm{gm}(11.88 \%)$.

Table 2: Organoleptic characters of formulation

\begin{tabular}{|c|l|l|l|l|}
\hline S.No & Parameters & Powder & Cream base & $\begin{array}{l}\text { Lepa Formulation } \\
\text { (powder + Cream } \\
\text { Base) }\end{array}$ \\
\hline 1 & Color & $\begin{array}{l}\text { Yellowish - } \\
\text { brown }\end{array}$ & Bright Yellow & Yellowish - Green \\
\hline 2 & Odor & Characteristic & Characteristic & Characteristic \\
\hline 3 & Touch & Coarse Powder & Greasy & Greasy \\
\hline 4 & Consistency & Soft & Soft & Soft \\
\hline 5 & Texture & Gritty & Smooth & Gritty \\
\hline 6 & Spreadibility & NA & $28.26 \mathrm{~cm}^{2}$ & $19.63 \mathrm{~cm}^{2}$ \\
\hline 7 & Loss on drying & $5.5 \mathrm{~g}$ & NA & $14.5 \mathrm{~g}$ \\
\hline 8 & $\%$ Loss & $5 \%$ & NA & $11.88 \%$ \\
\hline 9 & Ash value $\%$ w/w & $3.5 \%$ & NA & $1 \%$ \\
\hline 12 & pH (5\% $/ w$ Aqua solution) & 7.4 & 7.4 & 7.6 \\
\hline 13 & Skin Irritation Test & NA & $\begin{array}{l}\text { Non - } \\
\text { irritable }\end{array}$ & Non - irritable \\
\hline
\end{tabular}


In addition, the formulation was found to be non-irritating, and it was found to improve the skin texture immediately after the initial application with no further extra need for moisturizing agents.

Herbs have been used for beautification from historic times and have also been described in Ayurvedic literature. Herbs as whole plants or herbal extracts have been used to treat various ailments related to skin, hair, body odor, and overall beautification. ${ }^{[8]}$ Ayurveda, or Ayurvedic medicine, is gaining popularity among the beauty industry because it is effective, cheaper, and long-lasting with no side effects. The herbal paste that is applied to the face to treat 'Mukhdushika' is called 'Mukha Lepa' (face pack). Mukhdushika is derived from two words, 'Mukha' meaning the face, and 'Dushika', meaning impurity causing pigmentation, pimples, acne, scars, marks, or any other ailments. ${ }^{[9,10]}$ In the present study, the new herbal Lepa has been formulated with added moisturizing constituents and evaluated for its effectiveness.

It was found that the formulation was easy to apply, easy to wash, and slightly alkaline $\mathrm{pH}$ compatible with normal skin physiology. There were no signs of skin dryness. The formulation has moisturizing constituents, which offers no need for extra moisturizing agents. Based on the results, the formulation proved suitable for the application, comply with the requirements, and do not cause irritation.

\section{CONCLUSION}

There is a drastic rise in demand for herbal formulations because the belief that they are safer and cause fewer side effects than synthetic formulations. A newly developed herbal Lepa product has exhibited good cosmetic properties without the need of moisturizing creams. As a result of its fairness herbal components, Lepa cream will facilitate skin beautification by reducing skin pigmentation, melasma, acne marks, and skin lightening.

\section{ACKNOWLEDGMENT}

I would like to thank Ms. Vandana Thakur and Ms. Garima Agarwal, Assistant Professors at Meerut

\section{Cite this article as:}

Tejaswini Singh. Herbal Lepa Formulation Preparation and its Evaluation. International Journal of Ayurveda and Pharma Research. 2021;9(8):16-19.

https://doi.org/10.47070/ijapr.v9i8.1882

Source of support: Nil, Conflict of interest: None Declared
Institute of Engineering and Technology, Uttar Pradesh, for providing necessary assistance in this study.

\section{REFERENCES}

1. Zaigham, Hamiduddin, Tauheed A, Ali A, Recent Trend in Traditional Medicine Dosage Form and Present Status of Unani and Ayurvedic Medicine. International Journal of Pharmaceutical Sciences and Research. 2019; 10(4): 1640-49.

2. Patil S, Chaudhar AK, Topical dosages forms (Lepa Kalpana) of Ayurveda: An unexplored treasure. International Journal of Green Pharmacy. 2015: 9(4): S12-S19.

3. Chaudhari TG, Sneha K, Mukund D, Pallavi J, Role Of Lepakalpana For Improving Beauty of Skin W. S. R. To Mukhalepa. International Journal of Ayurveda and Pharma Research. 2017; 5(5): 72-77.

4. Angadi Ravindra. Textbook of Bhaishajya Kalpana Vijnana. Edition-II. Varanasi; Chaukhamba Surbharti Prakashan; 2016. p. 349-359.

5. Rani, S. R. and Hiremanth. Text book of Industrial pharmacy, Drug delivery systems \& Cosmetics \& Herbal drug technology. Edition-II. Universities press (India) Ltd. 2002.

6. Millikan LE, Cosmetology, cosmetics, cosmeceuticals: definitions and regulations. Clinics in Dermatology. 2001: 19(4): 371-374.

7. Rao M, Sukre G, Aghav S, Kumar M, Optimization of Metronidazole Emulgel, Journal of Pharmaceutics. 2013, 2013:1-9.

8. Kaur K, Thakur GS, Dhiman S, Arora S, Babbar R, Novel Herbs Used In Cosmetics For Skin And Hair Care: A Review. Plant Archives. 2020; 20 (Supplement 1): 3784-3793.

9. Chaudhari TG, Sneha K, Mukund D, Pallavi J, Role Of Lepakalpana For Improving Beauty of Skin W. S. R. To Mukhalepa. International Journal of Ayurveda and Pharma Research. 2017; 5(5): 72-77.

10. Shrivastava Shailaja. Sharangadhar samhita. (Uttarakhanda 11). Jeevanprada Hindi Commentary. Edition-4. Varanasi; Chaukhamba Orientalia Publication; 2005. P. 424-428.

\section{*Address for correspondence} Dr. Tejaswini Singh

Founder, Organic Greens Products and Botaniqal Naturopathy Consultancy

Mobile No: +91-8601332255

Email: tejaswini.singh@gmail.com

Disclaimer: IJAPR is solely owned by Mahadev Publications - dedicated to publish quality research, while every effort has been taken to verify the accuracy of the content published in our Journal. IJAPR cannot accept any responsibility or liability for the articles content which are published. The views expressed in articles by our contributing authors are not necessarily those of IJAPR editor or editorial board members. 